\title{
Risk factors for diagnostic delay in idiopathic pulmonary fibrosis
}

\author{
Nils Hoyer ${ }^{1 *}$ (D) Thomas Skovhus Prior ${ }^{2}$, Elisabeth Bendstrup ${ }^{2}$, Torgny Wilcke ${ }^{1}$ and Saher Burhan Shaker ${ }^{1}$
}

\begin{abstract}
Background: Surveys and retrospective studies of patients with idiopathic pulmonary fibrosis (IPF) have shown a significant diagnostic delay. However, the causes and risk factors for this delay are not known.

Methods: Dates at six time points before the IPF diagnosis (onset of symptoms, first contact to a general practitioner, first hospital contact, referral to an interstitial lung disease (ILD) centre, first visit at an ILD centre, and final diagnosis) were recorded in a multicentre cohort of 204 incident IPF patients. Based on these dates, the delay was divided into specific patient-related and healthcare-related delays. Demographic and clinical data were used to determine risk factors for a prolonged delay, using multivariate negative binomial regression analysis.
\end{abstract}

Results: The median diagnostic delay was 2.1 years (IQR: 0.9-5.0), mainly attributable to the patients, general practitioners and community hospitals. Male sex was a risk factor for patient delay (IRR: 3.84, 95\% Cl: 1.17-11.36, $p=$ 0.006 ) and old age was a risk factor for healthcare delay (IRR: 1.03, 95\% Cl: 1.01-1.06, $p=0.004$ ). The total delay was prolonged in previous users of inhalation therapy (IRR: 1.99, 95\% Cl: 1.40-2.88, $p<0.0001$ ) but not in patients with airway obstruction. Misdiagnosis of respiratory symptoms was reported by $41 \%$ of all patients.

Conclusion: Despite increased awareness of IPF, the diagnostic delay is still 2.1 years. Male sex, older age and treatment attempts for alternative diagnoses are risk factors for a delayed diagnosis of IPF. Efforts to reduce the diagnostic delay should focus on these risk factors.

Trial registration: This study was registered at http://clinicaltrials.gov (NCT02772549) on May 10, 2016.

Keywords: IPF, Diagnosis, Delay, Cohort, Observational

\section{Background}

Idiopathic Pulmonary Fibrosis (IPF) is a debilitating chronic lung disease. Despite recent advances in antifibrotic therapy, the prognosis is poor with a median survival of $2-5$ years $[1,2]$. The diagnosis of IPF can be challenging, and due to its rarity, few physicians gain enough expertise to become familiar with the disease. In addition, the diagnosis often requires a multidisciplinary team, which is not available in all centres [3, 4]. Surveys and retrospective studies have shown a significant diagnostic delay from the onset of symptoms until the final diagnosis is made [5-8]. This results in a delayed start of effective antifibrotic treatment and lung transplant evaluation, and can affect the disease course and

\footnotetext{
* Correspondence: nils.hoyer@regionh.dk

${ }^{1}$ Department of Respiratory Medicine, Herlev and Gentofte Hospital,

Kildegårdsvej 28, 2900 Hellerup, Denmark

Full list of author information is available at the end of the article
}

prognosis [5]. Current medical treatment of IPF can slow down the progression of the disease but does not seem to reverse any fibrotic changes that already have occurred [9-11]. Timely diagnosis is therefore important in order to initiate early treatment, prevent lung tissue from developing fibrosis, delay disease progression and prolong survival $[4,8]$.

The cause of the diagnostic delay is not well known but is probably multifactorial. Surveys suggest that misinterpretation of respiratory symptoms could be a contributing factor $[6,12]$. The first symptoms of IPF are often cough and shortness of breath, which are often attributed to old age, smoking or more common cardiovascular or respiratory diseases by either the patient or healthcare professionals as it is the case in patients with chronic obstructive pulmonary disease (COPD) [13]. The distribution of the diagnostic delay between patient-related and healthcare-related causes is still 
largely unknown. Moreover, we are not aware of any studies detailing the risk factors for a delayed diagnosis. A thorough understanding of these risk factors is essential for any attempts to reduce the diagnostic delay.

To answer these questions, we used a well characterized multicentre cohort of incident IPF patients to investigate the diagnostic delay and determine specific risk factors for a delayed diagnosis.

\section{Materials and methods}

\section{Patient cohort}

The Pulmonary Fibrosis Biomarker (PFBIO) cohort prospectively recruits incident patients with IPF from two large interstitial lung disease (ILD) centres in Denmark serving a population of 4.2 million. The main purpose of the cohort is to follow a broad population of patients with IPF and create a biorepository for biomarker research. Antifibrotic therapy is centralized in Denmark and referral to one of the three specialized ILD centres is necessary for patients to be eligible for treatment. Recruitment for the PFBIO cohort started in 2016 and is still ongoing at one of the participating centres (Gentofte Hospital) for future studies. At the time of analysis, the cohort had included 204 patients. All participants had received a diagnosis of IPF according to the 2011 ATS/ ERS/JRS/ALAT guidelines at an ILD centre, based on a multidisciplinary team approach [3, 14]. Patients were recruited on the same day as they received the diagnosis or up to a maximum of two months later but prior to initiating antifibrotic treatment. All patients with IPF were eligible for participation unless they were unable to provide written informed consent. A flowchart of the recruitment process is presented in the Additional files 1.

\section{Data collection}

Patients completed a detailed survey at the time of diagnosis which was followed up by an interview if needed for clarification (see Additional file 1). The survey included questions about the onset of symptoms, initial healthcare contact, smoking history, alternative diagnoses for respiratory symptoms, and previous therapies. The patients' quality of life was assessed by the St. George's Respiratory Questionnaire (SGRQ) with higher scores indicating worse quality of life [15]. Several measures of disease severity were collected from the patients' electronic records: comprehensive pulmonary function tests with spirometry and diffusing capacity for carbon monoxide (DLCO), six-minute walk test (6MWT) and high resolution computed tomography (HRCT) scan.

The diagnostic delay was calculated based on six pre-defined time points on the patients' path towards an IPF diagnosis (Fig. 1). The first two time points (dates of symptom onset and first contact with a general practitioner) were part of the survey which was completed by each patient shortly after their diagnosis. All remaining time points were collected from the patients' electronic records. The specific delays were calculated from these time points and are illustrated in Fig. 1. If a time point was not relevant in a patient's path towards an IPF diagnosis (i.e. if the first contact with a physician was at a community hospital or if a patient was referred directly to an ILD centre by the general practitioner), the jumped delay was excluded for that patient in the statistical analysis.

\section{Statistical analysis}

Descriptive data are presented as frequency tables, mean (SD) or median (interquartile range, IQR) as appropriate for the data. Univariate analyses of baseline characteristics were performed with a t-test or chi-squared test as appropriate for the data.

None of the specific delays were normally distributed and are presented as medians with IQR. We used multivariate negative binomial regression models to determine specific risk factors for patient delay, healthcare delay and total delay respectively, as the delays were counts of days and did not fit a Poisson distribution.

Covariates were tested for normality before inclusion into any statistical analysis. Missing data were handled by listwise deletion using complete cases without any imputation of data.

\section{Ethics, consent and permissions}

All participants were included after written informed consent, and none had chosen to withdraw from the study at the time of analysis. The study has been approved by the Capital Region regional ethics committee (H-16001790) and the Danish Data Protection Agency (HGH-2016-017). The study was also registered at http://clinicaltrials.gov

Onset of First visit
Fig. 1 Diagnostic delay from patients' awareness of symptoms until an IPF diagnosis is made. The total delay is divided into patient delay and
healthcare delay (GP delay, hospital delay, waiting delay and specialized delay combined)


(NCT02772549). We conducted the study according to the principles of the Declaration of Helsinki and adhered to the STROBE guidelines.

\section{Results}

The baseline characteristics of the 204 participants in the PFBIO cohort are listed in Table 1. Patients were stratified according to length of total diagnostic delay above or below 2 years. Demographic data such as age and sex were similar in both groups, but there was a trend towards more never-smokers among patients with a long total delay (Table 1). Patients with a total delay of more than two years were more frequently treated with inhalation therapy prior to their diagnosis but without a marked increase in airway obstruction, defined by a $\mathrm{FEV}_{1} / \mathrm{FVC}$ ratio below 0.7 (Table 1). Patients with a long delay also tended to have a higher SGRQ total score and more frequently had a UIP pattern on the diagnostic HRCT, which however did not reach statistical significance (Table 2). Although rarely performed, transbronchial cryobiopsies were more common in patients with a short delay (Table 2). We were unable to calculate total delay for 14 patients, due to imprecise data about their onset of symptoms. Baseline data for this group is presented in the Additional file 1.

\section{Referral pattern}

Forty (20\%) patients reported three or more visits to their general practitioner before being referred further to a secondary care hospital. When referred to the ILD centres, the majority of patients had been investigated at other community hospitals $(n=169,83 \%)$, and only rarely were referred directly from a private respiratory physician $(n=6,3 \%)$ or a general practitioner $(n=29$, $14 \%)$. The IPF diagnosis was already suggested at the

Table 1 Baseline characteristics of participants with a delay above or below 2 years

\begin{tabular}{|c|c|c|c|c|}
\hline & All patients $(n=204)$ & Total delay $>2$ years $(n=98)$ & Total delay $<2$ years $(n=92)$ & $P$-value \\
\hline Age (years), mean (SD) & $73.7(7.8)$ & $73.2(8.0)$ & $73.5(7.6)$ & 0.79 \\
\hline Sex & & & & 0.79 \\
\hline Male, n (\%) & $158(77.5 \%)$ & $74(75.5 \%)$ & $71(77.2 \%)$ & \\
\hline Female, n (\%) & $46(22.5 \%)$ & $24(24.5 \%)$ & $21(22.8 \%)$ & \\
\hline Smoking status & & & & 0.28 \\
\hline Never, n (\%) & $52(25.6 \%)$ & $31(31.6 \%)$ & $20(21.7 \%)$ & \\
\hline Active, n (\%) & $14(6.9 \%)$ & $6(6.1 \%)$ & $8(8.7 \%)$ & \\
\hline Former, n (\%) & $137(67.5 \%)$ & $61(62.2 \%)$ & $64(69.6 \%)$ & \\
\hline Pack-years, median (IQR) & $25.0(11.8-40.0)$ & $26.5(10.9-40.0)$ & $20.0(10.8-41.7)$ & 0.68 \\
\hline BMI $\left(\mathrm{kg} / \mathrm{m}^{2}\right)$, mean $(\mathrm{SD})$ & $27.4(4.6)$ & $28.0(4.4)$ & $26.8(4.9)$ & 0.08 \\
\hline Education & & & & 0.67 \\
\hline No higher education, n (\%) & $101(54.9 \%)$ & $52(56.5 \%)$ & $47(53.4 \%)$ & \\
\hline Higher education, n (\%) & $83(45.1 \%)$ & $40(43.5 \%)$ & $41(46.6 \%)$ & \\
\hline Previous use of inhalation therapy & & & & $<0.01$ \\
\hline No, n (\%) & $143(70.1 \%)$ & $59(60.2 \%)$ & $76(82.6 \%)$ & \\
\hline Yes, n (\%) & $61(29.9 \%)$ & 39 (39.8\%) & $16(17.4 \%)$ & \\
\hline Airway obstruction at baseline & & & & 0.75 \\
\hline No, n (\%) & $179(88.2 \%)$ & 87 (88.8\%) & $83(90.2 \%)$ & \\
\hline Yes, n (\%) & $24(11.8 \%)$ & $11(11.2 \%)$ & $9(9.8 \%)$ & \\
\hline FVC (I), mean (SD) & $3.0(0.8)$ & $3.0(0.8)$ & $3.1(0.9)$ & 0.60 \\
\hline FVC (\% pred.), mean (SD) & $88.9(19.0)$ & $87.9(16.8)$ & $91.1(21.6)$ & 0.25 \\
\hline DLCO (\% pred.), mean (SD) & $52.6(13.6)$ & $52.6(13.6)$ & $53.0(13.5)$ & 0.84 \\
\hline 6MWT-distance (m), mean (SD) & $441.7(106.5)$ & $444.8(108.1)$ & $448.3(93.2)$ & 0.82 \\
\hline $\mathrm{SaO} 2$ at rest (\%), mean (SD) & $96.2(1.9)$ & $96.3(1.8)$ & $96.2(1.9)$ & 0.82 \\
\hline $\mathrm{SaO} 2$ after 6MWT (\%), mean (SD) & $88.2(7.7)$ & $88.2(7.0)$ & $88.3(8.2)$ & 0.92 \\
\hline SGRQ total score, mean (SD) & $39.1(19.6)$ & $41.4(17.8)$ & $37.2(21.4)$ & 0.20 \\
\hline
\end{tabular}

$S D$ standard deviation, IQR interquartile range, FVC forced vital capacity, DLCO diffusion capacity for carbon monoxide, $6 M W T$ six-minute walk test, SGRQ St. George's Respiratory Questionnaire

Total delay could not be calculated for 14 patients due to the lack of data about onset of symptoms (baseline data of these patients are listed in the Additional file). Airway obstruction was defined as FEV1/FVC $<0.7$ 
Table 2 Diagnostic procedures performed for the IPF diagnosis

\begin{tabular}{|c|c|c|c|c|}
\hline & All patients $(n=204)$ & Total delay > 2 years $(n=98)$ & Total delay < 2 years $(n=92)$ & $P$-value \\
\hline \multicolumn{4}{|l|}{ HRCT pattern } & \multirow[t]{4}{*}{0.27} \\
\hline UIP, n (\%) & $142(73.2 \%)$ & 75 (78.1\%) & $59(67.8 \%)$ & \\
\hline Possible UIP, n (\%) & 39 (20.1\%) & $16(16.7 \%)$ & $20(23.0 \%)$ & \\
\hline Not UIP, n (\%) & $13(6.7 \%)$ & $5(5.2 \%)$ & $8(9.2 \%)$ & \\
\hline \multicolumn{5}{|l|}{ BAL performed } \\
\hline No, n (\%) & $120(58.8 \%)$ & $60(61.2 \%)$ & 49 (53.3\%) & \multirow[t]{2}{*}{0.27} \\
\hline Yes, n (\%) & $84(41.2 \%)$ & $38(38.8 \%)$ & $43(46.7 \%)$ & \\
\hline \multicolumn{4}{|c|}{ Surgical lung biopsy performed } & \multirow[t]{3}{*}{0.25} \\
\hline No, n (\%) & $180(88.2 \%)$ & $83(84.7 \%)$ & $83(90.2 \%)$ & \\
\hline Yes, n (\%) & $24(11.8 \%)$ & $15(15.3 \%)$ & $9(9.8 \%)$ & \\
\hline \multicolumn{4}{|l|}{ Cryobiopsy performed } & \multirow[t]{3}{*}{0.02} \\
\hline No, n (\%) & $188(92.2 \%)$ & 95 (96.9\%) & 81 (88.0\%) & \\
\hline Yes, n (\%) & $16(7.8 \%)$ & $3(3.1 \%)$ & $11(12.0 \%)$ & \\
\hline \multicolumn{4}{|c|}{ Velcro crackles on lung auscultation } & \multirow[t]{3}{*}{0.32} \\
\hline No, n (\%) & $26(13.6 \%)$ & $13(14.1 \%)$ & $8(9.3 \%)$ & \\
\hline Yes, n (\%) & $165(86.4 \%)$ & 79 (85.9\%) & 78 (90.7\%) & \\
\hline
\end{tabular}

$H R C T$ high resolution computed tomography, UIP usual interstitial pneumonia, BAL Bronchoalveolar lavage

The HRCT pattern is classified according to 2011 ATS/ERS/JRS/ALAT guidelines [12]

referring community hospital in 18 (9\%) patients before referral.

Most patients from community hospitals were referred from a department of respiratory medicine $(n=133$, $65 \%)$. Fewer patients were referred from departments of internal medicine $(n=17,8 \%)$, cardiology $(n=5,2 \%)$, emergency departments $(n=3,1 \%)$ or other departments $(n=10,5 \%)$.

We were able to calculate a total incidence of 2.9 IPF patients per 100,000 persons per year for the eastern part of the country (served by one of the participating ILD centres) where complete data were available. Data on incident IPF patients who were not included in the cohort were not available from other centres and these could thus not be used in estimating the incidence (see Additional file 1 for details).

\section{Diagnostic delay}

The median total diagnostic delay was 2.1 years (IQR: 0.9-5.0) and was stable during the study period (see Additional file 1). The delay was mainly attributable to:

1) The patients (onset of symptoms until the first healthcare contact) with a median delay of 0.1 years (IQR: 0-0.9) (Fig. 2).

2) The general practitioners (first contact with a general practitioner until referral to secondary healthcare) with a median delay of 0.4 years (IQR: 0.2-1.2) (Fig. 2).
3) The community hospitals (first visit due to the current respiratory symptoms until referral to an ILD centre) with a median delay of 0.4 years (IQR: 0.1-1.9) (Fig. 2).

The delay due to waiting time (referral to an ILD centre until the first patient visit at this hospital) was 0.2 years (IQR: 0.1-0.3) and the specialized diagnostic workup (first visit at the ILD centre until the final diagnosis) was 0.1 years (IQR: 0-0.3) (Fig. 2). As the diagnostic HRCT scan typically was performed during the waiting time, the median time from the HRCT scan until the final diagnosis was 0.3 years (IQR: $0.1-0.4$ ). Due to highly skewed data of all specific delays, the median total delay was longer than the sum of all specific median delays (Fig. 2).

\section{Risk factors for diagnostic delay}

In multivariate negative binomial regression analysis, patient delays were prolonged in males and previous inhalation therapy users. Healthcare delays were prolonged in older patients and previous inhalation therapy users. The combined total delay was prolonged in previous inhalation therapy users but not influenced by sex, age or proven obstructive lung disease (Table 3, Fig. 3).

Clinical findings at the time of diagnosis were also associated with the diagnostic delay (Table 3). Longer patient delays and healthcare delays were associated with preserved DLCO and high SGRQ total score at the time of diagnosis. Consequently, longer total delays were also associated with preserved DLCO, high SGRQ total score 


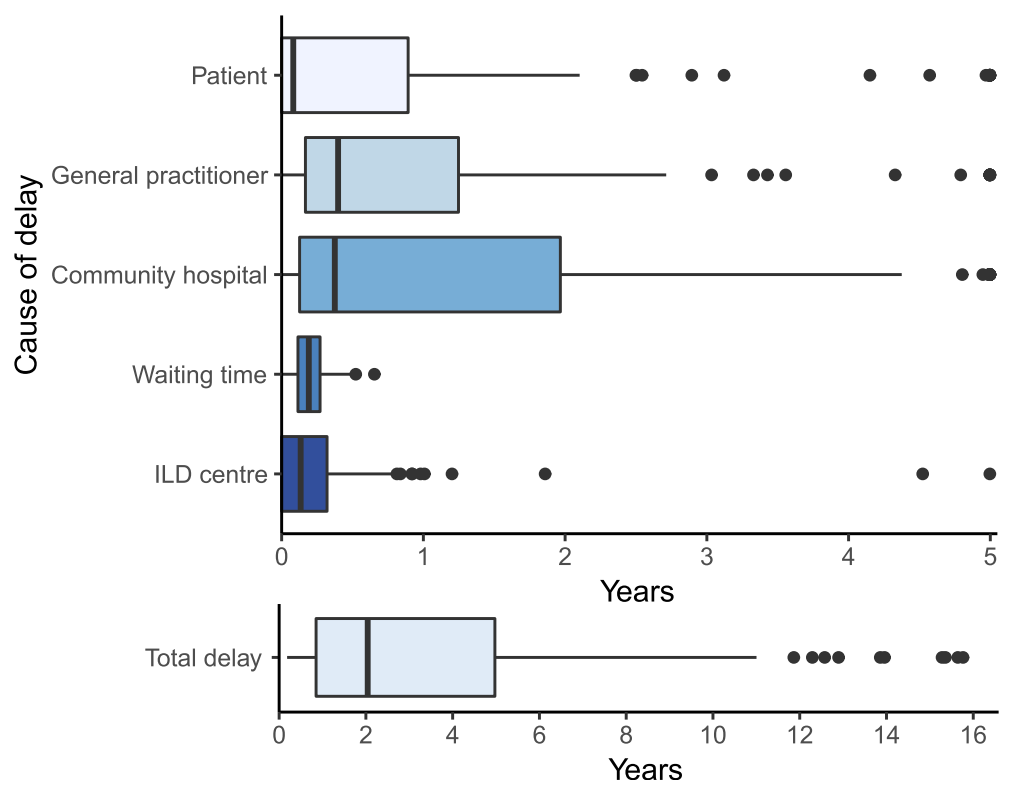

Fig. 2 Duration (median, IQR) of total and specific delays due to patient, general practitioner, community hospitals, waiting time and ILD centres. Time periods of the specialized delays are truncated at 5 years to increase legibility. Note different time scales

but also a usual interstitial pneumonia (UIP) pattern on HRCT at the time of diagnosis (Table 3).

\section{Alternative diagnoses and treatments}

Misdiagnosis was common with respiratory symptoms being attributed to at least one alternative diagnosis in $82(41 \%)$ participants before an IPF diagnosis was established (Table 4). Of these, 62 had received treatment for the alternative diagnosis for a median duration of 7.0 months. Heart disease was the most common misdiagnosis $(n=25,12 \%)$ followed by obstructive lung disease (Table 4). However, of the 61 participants with a history of inhalation therapy use, only 20 (33\%) fulfilled the diagnostic criteria for either asthma or COPD. Treatment with inhalation therapy increased the total diagnostic delay in patients with and without proven obstructive lung disease (Fig. 3).

Table 3 Incidence rate ratio (IRR) of several risk factors for patient delay, healthcare delay and total delay, assessed by multivariate negative binomial regression

\begin{tabular}{|c|c|c|c|c|c|c|c|c|c|}
\hline & \multicolumn{3}{|c|}{ Patient delay } & \multicolumn{3}{|c|}{ Healthcare delay } & \multicolumn{3}{|c|}{ Total delay } \\
\hline & IRR & $95 \% \mathrm{Cl}$ & $p$-value & $\mathrm{IRR}$ & $95 \% \mathrm{Cl}$ & $p$-value & IRR & $95 \% \mathrm{Cl}$ & $p$-value \\
\hline \multicolumn{10}{|l|}{ Patient characteristics } \\
\hline Age & 0.97 & $0.92-1.02$ & 0.24 & 1.03 & $1.01-1.06$ & $0.004^{*}$ & 1.01 & $0.98-1.03$ & 0.59 \\
\hline Male sex & 3.84 & $1.17-11.36$ & $0.006^{*}$ & 1.01 & $0.68-1.49$ & 0.95 & 0.99 & $0.66-1.48$ & 0.97 \\
\hline Ever smokers & 1.34 & $0.48-3.35$ & 0.51 & 0.78 & $0.54-1.11$ & 0.18 & 0.79 & $0.54-1.14$ & 0.19 \\
\hline Higher education & 2.16 & $0.91-5.18$ & 0.06 & 1.28 & $0.91-1.81$ & 0.14 & 1.15 & $0.83-1.60$ & 0.39 \\
\hline Previous use of inhalation therapy & 4.68 & $1.77-13.37$ & $0.0004^{*}$ & 1.98 & $1.38-2.90$ & $<0.0001^{*}$ & 1.99 & $1.40-2.88$ & $<0.0001^{*}$ \\
\hline \multicolumn{10}{|l|}{ Clinical findings at diagnosis } \\
\hline DLCO (\%) & 1.05 & $1.02-1.08$ & $0.005^{*}$ & 1.02 & $1.01-1.03$ & $0.006^{*}$ & 1.02 & $1.00-1.03$ & $0.02^{*}$ \\
\hline FVC (\%) & 1.02 & $0.99-1.05$ & 0.06 & 1.00 & $0.99-1.01$ & 0.96 & 1.00 & $0.99-1.01$ & 0.67 \\
\hline Airway obstruction & 1.10 & $0.23-3.86$ & 0.89 & 1.57 & $0.86-2.66$ & 0.11 & 1.61 & $0.94-2.61$ & 0.07 \\
\hline SGRQ total score & 1.03 & $1.01-1.07$ & $0.004^{*}$ & 1.01 & $1.00-1.03$ & $0.003^{*}$ & 1.02 & $1.01-1.03$ & $0.001^{*}$ \\
\hline UIP pattern on HRCT & 0.84 & $0.30-2.11$ & 0.71 & 1.32 & $0.89-1.95$ & 0.16 & 1.47 & $1.01-2.11$ & $0.04^{*}$ \\
\hline
\end{tabular}

Cl confidence interval, DLCO diffusion capacity for carbon monoxide, $6 M W T$ six-minute walk test, SGRQ St. George's Respiratory Questionnaire, HRCT high resolution computed tomography, UIP usual interstitial pneumonia ${ }^{*} p$-value $<0.05$

Values of DLCO, FVC and SGRQ-score are obtained at the time of diagnosis. Airway obstruction is defined as FEV1/FVC $<0.7$ 


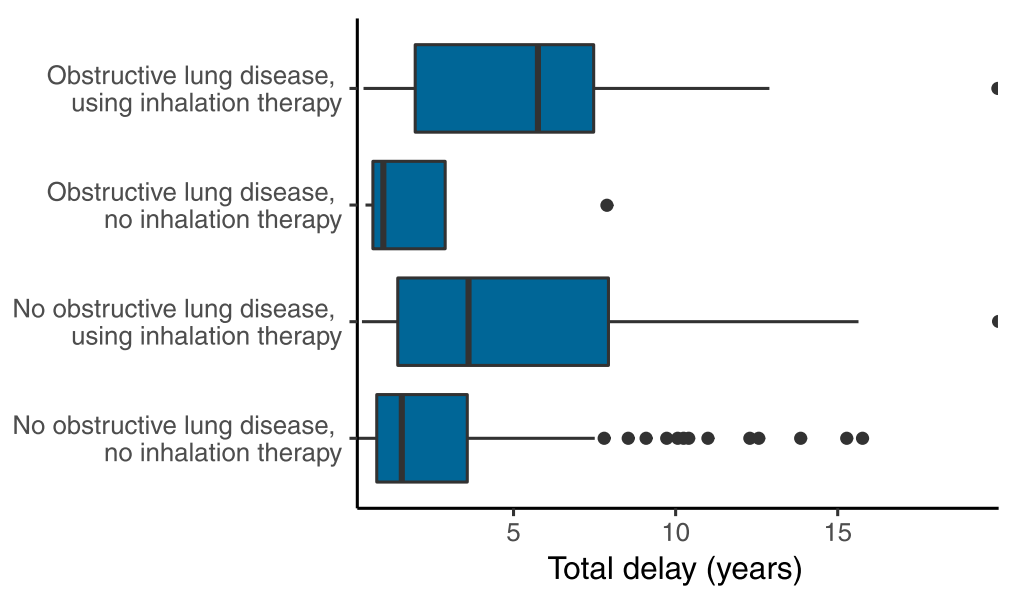

Fig. 3 Length of total delay in participants stratified according to obstructive lung disease (asthma or COPD) and previous use of inhalation therapy

A total of $51 \%$ of patients reported at least one occurrence of pneumonia during the two years before their IPF diagnosis, while $49 \%$ received treatment for at least one instance of pneumonia (Table 4).

Thirty-five (18\%) of all participants had received at least one prescription of prednisolone or other immunosuppressive treatment before referral. A large proportion of patients (42\%) had received a prescription of proton pump inhibitor (PPI) and 32\% also reported taking over-the-counter antacid therapy (Table 4). None of the patients were treated with specific antifibrotic treatment until they received their diagnosis of IPF at the ILD centres.

\section{Discussion}

We studied the referral pattern and diagnostic delay in a cohort of IPF patients and found that it was mainly attributable to patients, general practitioners and community hospitals. Previous inhalation therapy use was a major risk factor for a delayed diagnosis. Male sex was associated with a prolonged patient delay and older age was associated with a prolonged healthcare delay. Patients were often misdiagnosed and treated before a final diagnosis of IPF was made.

We present for the first time a detailed description of IPF patients' path towards the IPF diagnosis and the different components of the diagnostic delay in incident patients and thus with limited recall bias. We highlight the three main sources of delay: patients themselves, general practitioners and community hospitals (most commonly departments of respiratory medicine). Future efforts to reduce the diagnostic delay should be directed at these three sources which could be achieved by further increasing awareness of IPF among patients, general practitioners and hospital physicians (both pulmonologists and other specialists). However, while the delay at ILD centres often was shorter, it still contributed to the total delay in many patients and the median time from the diagnostic HRCT until the final diagnosis was still 0.3 years. Therefore, there is a potential for interventions to shorten the delay at all steps towards the IPF diagnosis, which should be further explored. A delay, however, is not always the result of a mistake or missed diagnosis. It is possible that some patients were delayed because they did not fulfil diagnostic criteria for IPF during the early stages of their disease, which is a recognized limitation of the 2011 ATS/ERS/JRS/ALAT guidelines [16].

We expected a shortened diagnostic delay due to an increased awareness of IPF during recent years which unfortunately could not be confirmed. The availability of pharmacological treatments during the past few years resulted in an increase in the number of patients referred to ILD centres, but this increase has so far failed to impact the diagnostic delay in IPF [7]. We found a median total diagnostic delay of 2.1 years, which is similar to previous reports of IPF patients and general ILD populations, despite new treatment options, new diagnostic guidelines and increased awareness of IPF [4-8, 17-20].

In addition to the median length of the diagnostic delay of 2.1 years, we found a high spread of the specific and total delays with $25 \%$ of patients having a delay of more than 5 years. This finding contributes to the evolving understanding that some patients with IPF can have a slowly progressive phenotype [1]. However, some patients reported very long delays of up to 20 years, which are unlikely to be due to symptoms caused by IPF. Rather, the patient-reported symptoms could be caused by an alternative disease, such as cardiovascular disease or COPD, which are common comorbidities in patients with IPF [21]. In addition, recall bias can affect the patients' ability to remember important information about the onset of their symptoms. However, the specific healthcare delays are defined by objective data from 
Table 4 Previous diagnosis and treatment before an IPF diagnosis was made

\begin{tabular}{ll}
\hline & All patients $(\mathrm{n}=204)$ \\
\hline Alternative diagnoses for respiratory symptoms & \\
Heart disease & $25(12.3 \%)$ \\
Asthma & $17(8.3 \%)$ \\
Chronic bronchitis & $11(5.4 \%)$ \\
COPD & $10(4.9 \%)$ \\
Emphysema & $3(1.5 \%)$ \\
Other & $18(8.8 \%)$
\end{tabular}

Reports of pneumonia during the previous 2 years before IPF diagnosis

$\begin{array}{ll}0 & 88(49.2 \%) \\ 1 & 32(17.9 \%) \\ 2 & 28(15.6 \%) \\ 3 \text { or more } & 31(18.0 \%)\end{array}$

Antibiotic courses for pneumonia during the previous 2 years before IPF diagnosis

$\begin{array}{ll}0 & 91(50.6 \%) \\ 1 & 35(19.4 \%) \\ 2 & 31(17.2 \%) \\ 3 \text { or more } & 23(11.3 \%)\end{array}$

Previous medical treatments

Inhalation therapy

$\begin{array}{ll}\text { SABA } & 39(19.1 \%) \\ \text { LABA } & 29(14.2 \%) \\ \text { LAMA } & 21(10.3 \%) \\ \text { ICS } & 26(12.7 \%) \\ \text { Prednisolone } & 34(16.7 \%) \\ \text { Other immunosuppressive treatment }{ }^{\mathrm{a}} & 5(2.5 \%) \\ \text { Proton pump inhibitor or H2-receptor antagonist } & 85(41.7 \%) \\ \text { Antacids } & 57(31.7 \%)\end{array}$

SABA short acting beta agonist, $\angle A B A$ long acting beta agonist, $L A M A$ long acting muscarinic antagonist, ICS inhaled corticosteroid. ${ }^{a}$ Azathioprine $(n=2)$, mycophenolate mofetil, oral budesonide and cyclophosphamide (each $n=1$ )

electronic records and support the hypothesis of a phenotype with slowly progressive IPF. The possible identification of interstitial lung abnormalities on lung CT many years prior to the development of clinical interstitial lung disease further contributes to this observation [22-24].

A first step to reduce the diagnostic delay is to identify risk factors for a delay and recognize target groups for interventions. We are unaware of previous studies providing estimates of risk factors for a delayed diagnosis of IPF. Interestingly, the risk factors for patient delay differ from those for healthcare delay. The previous use of inhalation therapy and male sex were risk factors for a prolonged patient delay. The increased delay in previous inhalation therapy users could be attributable to treatment attempts with inhalation therapy for unexplained respiratory symptoms in the primary care sector, which has been suggested previously [12, 18]. Airway obstruction was not a risk factor for a diagnostic delay, which indicates frequent futile treatment attempts with inhalation therapy in patients without obstructive lung disease. However, it is possible that an obstructive lung disease was masked by a concomitant reduction in FVC in some patients. While treatment attempts with inhalation therapy can be warranted in patients with unexplained respiratory symptoms, these patients should be closely monitored and referred for further workup when symptoms do not improve. In addition, a correctly performed and interpreted spirometry could help to quickly rule out airway obstruction as a cause of breathlessness in these patients. Improved diagnostic tools, including screening or effective diagnostic biomarkers, would make the diagnosis more accessible, also for non-ILD specialists, and are desperately needed.

Patients with a prolonged delay had relatively preserved DLCO at the time of diagnosis, suggesting that patients with more severe IPF were quickly diagnosed. On the other hand, patients with a prolonged delay reported a high symptom burden as indicated by a higher SGRQ total score. This apparent discrepancy could be explained by the complexity of quality of life data, which can be impacted by many factors, including a prolonged diagnostic delay but also by comorbidities, misdiagnosis, treatment and multiple healthcare contacts. Besides, the SGRQ total score has limitations in quantifying disease severity in IPF patients [25].

Patients reported frequent misdiagnosis prior to their final IPF diagnosis, which is in line with the presented risk factors for a diagnostic delay, and with previous patient surveys $[12,17,20]$. The frequent treatment with inhalation therapy for obstructive lung disease, despite the lack of airway obstruction, confirms this problem. In addition, the previous treatments were often given for long periods (median duration of treatment was 7.0 months) and included potentially harmful treatments such as prednisolone and other immunosuppressive drugs, which are often prescribed for other fibrotic lung disease such as chronic hypersensitivity pneumonitis, a common differential diagnosis to IPF. The frequent occurrences of pneumonia in the two years prior to the IPF diagnosis could either be due to an increased risk of infection in patients or misinterpretation of crackles on auscultation. Screening for finger clubbing and velcro crackles on auscultation, particularly if they do not resolve after treatment of suspected pneumonia, should prompt further diagnostic evaluation [26]. A treatment attempt for any suspected disease prolongs the diagnostic delay, and most importantly delays the initiation of effective antifibrotic treatment. Early referral of patients 
with an uncertain diagnosis to a centre with expertise in ILD is essential and could contribute to shortening the diagnostic delay.

Based on data from one participating centre, we could estimate an annual incidence of 2.9 IPF patients per 100,000 inhabitants per year. However, it might be suspected that some older and frail patients, or patients with severe comorbidities, were not referred for a diagnostic workup at an ILD centre. Our calculated incidence is in the lower end of the range of other estimates (0.6-17.4 cases of IPF per 100,000 inhabitants per year) which suggests a continuing underdiagnosis of IPF [27]. Previous reports have often been performed retrospectively or are based on registries and insurance claims (which can overestimate incidence due to miscoding) and many estimates predate the current diagnostic guidelines [27-29]. In contrast to several previous studies, all patients included in our cohort had a confident IPF diagnosis confirmed at a specialised ILD centre. A Danish study estimated the IPF incidence in 2003-2009 to be 1.3 patients per 100,000 inhabitants per year [7]. Thus, despite the apparent underdiagnosis, we can confirm a general increase in the incidence of IPF diagnosis in a comparable setting.

Our study has several strengths but also some limitations. A major strength is the prospective inclusion of a large part of all incident IPF patients in two ILD centres in the region increasing the generalizability of the results. In addition, we included patients immediately after their IPF diagnoses, thus reducing recall bias of important information, such as the date of symptom onset. However, as most patients experienced a diagnostic delay of several years, there remains a risk of recall bias in our cohort. Wherever possible, time points were extracted from electronic medical records, resulting in more reliable data compared with surveys with patient reported data. However, some data were still patient reported, and thus not entirely objective. This includes the date of symptom onset and the first healthcare contact. These data are inherently subjective and could not have been collected in a different manner. The definition of symptom onset can also be debated. Many patients with IPF have comorbidities which could give respiratory symptoms (i.e., cardiovascular disease or COPD) making it difficult to define the onset of symptoms caused by IPF. However, proven obstructive pulmonary disease was not a risk factor for a prolonged delay.

Our study was performed in one single country and findings cannot simply be generalized to other countries and healthcare systems. While treatment of IPF in Denmark is centralised to a few ILD centres, it may not be in other countries, potentially leading to more missed or delayed diagnoses. Also, the organization and responsibilities of primary, secondary and tertiary care differ between countries. Due to these differences, we considered the combined healthcare delay in the statistical analyses, rather than the specific delays (general practitioner, community hospital or ILD centre). Nevertheless, we believe that patients with IPF in other health systems will meet the same obstacles on their path towards a diagnosis of IPF, due to the rarity of the condition and the difficulty in establishing a confident diagnosis.

\section{Conclusion}

In conclusion, this study has shown that diagnostic delay in IPF is mainly attributable to patients, general practitioners and community hospitals. Patients were often misdiagnosed and treated before a final diagnosis of IPF was made. Previous inhalation therapy use was a major risk factor for a delayed diagnosis, and male sex and older age were risk factors for patient delay and healthcare delay respectively. Efforts to reduce the diagnostic delay should focus on these risk factors.

\section{Additional file}

Additional file 1: Figure S1. Recruitment and follow-up of participants in the PFBIO cohort. Centre A: Gentofte Hospital, Centre B: Aarhus University Hospital. Figure S2. Diagnostic delay length in all participants where the total delay was possible to calculate $(n=190)$. Table S1. Baseline data of participants without a calculated total delay available for analysis. (DOCX $73 \mathrm{~kb}$ )

\section{Abbreviations}

6MWT: 6-min walk test; COPD: Chronic obstructive pulmonary disease; DLCO: Diffusing capacity for carbon monoxide; HRCT: High Resolution computed tomography; ILD: Interstitial lung disease; IPF: Idiopathic pulmonary fibrosis; IQR: Interquartile range; PPI: Proton pump inhibitor; SGRQ: St. George's respiratory questionnaire; UIP: Usual interstitial pneumonia

\section{Acknowledgements}

We thank the dedicated staff at Gentofte Hospital and Aarhus University Hospital for their immense help with the project, which would not have been possible without them. We thank Roche a/s for their unrestricted research grant which has enabled us to build the PFBIO cohort. We also thank P.A. Messerschmidt og Hustrus Fond and Skibsreder Per Henriksen, R og Hustrus Fond for their unrestricted research grants.

\section{Funding}

This work was supported by P.A. Messerschmidt og Hustrus Fond, Skibsreder Per Henriksen, R. og Hustrus Fond and Roche a/s. None of the funding sources had any involvement in the study design, in the collection, analysis and interpretation of data, in the writing of the report or in the decision to submit the article for publication.

\section{Availability of data and materials}

The datasets generated and/or analysed during the current study are not publicly available due to restrictions by the Danish data protection laws but are available from the corresponding author on reasonable request.

\section{Authors' contributions}

$\mathrm{NH}$ and SBS designed the study. $\mathrm{NH}$ and TSP collected the data. $\mathrm{NH}$ performed the statistical analysis and drafted the manuscript. SBS, EB and TW contributed with continuous academic guidance and support during the study. All authors contributed to the interpretation of the results, critically revised the manuscript and have approved it in its final form. 


\section{Ethics approval and consent to participate}

All participants were included after written informed consent, and none had chosen to withdraw from the study at the time of analysis. The study has been approved by the Capital Region regional ethics committee $(\mathrm{H}-$ 16001790) and the Danish Data Protection Agency (HGH-2016-017). The study was also registered at clinicaltrials.gov (NCT02772549). We conducted the study according to the principles of the Declaration of Helsinki and adhered to the STROBE guidelines.

\section{Consent for publication}

Not applicable.

\section{Competing interests}

Dr. Hoyer reports grants from P.A. Messerschmidt og Hustrus Fond, grants from Skibsreder Per Henriksen, R. og Hustrus Fond and grants from Roche a/ $s$, during the conduct of the study. Dr. Skovhus Prior reports lecture fees from Roche A/S and Boehringer Ingelheim Denmark. Dr. Bendstrup reports grants, personal fees and other from Roche, grants, personal fees and other from Boehringer Ingelheim, outside the submitted work. Dr. Wilcke has nothing to disclose. Dr. Shaker reports lecture fees and travel expenses for participation in scientific meetings and congresses from Roche, Boehringer Ingelheim and AstraZeneca and payment for advisory board meetings arranged by Roche and Boehringer Ingelheim.

\section{Publisher's Note}

Springer Nature remains neutral with regard to jurisdictional claims in published maps and institutional affiliations.

\section{Author details}

'Department of Respiratory Medicine, Herlev and Gentofte Hospital, Kildegårdsvej 28, 2900 Hellerup, Denmark. ²Department of Respiratory Diseases and Allergy, Aarhus University Hospital, Nørrebrogade 44, 8000 Aarhus C, Denmark.

Received: 19 March 2019 Accepted: 16 May 2019

Published online: 24 May 2019

\section{References}

1. Ley B, Collard HR, King TE. Clinical course and prediction of survival in idiopathic pulmonary fibrosis. Am J Respir Crit Care Med. 2011;183:431-40. https://doi.org/10.1164/rccm.201006-0894Cl.

2. du Bois RM. An earlier and more confident diagnosis of idiopathic pulmonary fibrosis. Eur Respir Rev. 2012;21:141-6. https://doi.org/10.1183/ 09059180.00000812

3. Raghu G, Remy-Jardin M, Myers JL, et al. Diagnosis of idiopathic pulmonary fibrosis. An official ATS/ERS/JRS/ALAT clinical practice guideline. Am J Respir Crit Care Med. 2018;198:e44-68. https://doi.org/10.1164/rccm.2018071255ST.

4. Martinez FJ, Chisholm A, Collard HR, et al. The diagnosis of idiopathic pulmonary fibrosis: current and future approaches. Lancet Respir Med. 2017; 5:61-71. https://doi.org/10.1016/S2213-2600(16)30325-3.

5. Lamas DJ, Kawut SM, Bagiella E, et al. Delayed access and survival in idiopathic pulmonary fibrosis: a cohort study. Am J Respir Crit Care Med. 2011;184:842-7. https://doi.org/10.1164/rccm.201104-06680C.

6. Cosgrove GP, Bianchi P, Danese $\mathrm{S}$, et al. Barriers to timely diagnosis of interstitial lung disease in the real world: the INTENSITY survey. BMC Pulm Med. 2018;18:1-9. https://doi.org/10.1186/s12890-017-0560-x.

7. Hyldgaard C, Hilberg $\mathrm{O}$, Muller A, et al. A cohort study of interstitial lung diseases in Central Denmark. Respir Med. 2014;108:793-9. https://doi.org/10. 1016/j.rmed.2013.09.002.

8. Oldham JM, Noth I. Idiopathic pulmonary fibrosis: early detection and referral. Respir Med. 2014;108:819-29. https://doi.org/10.1016/j.rmed.2014.03. 008.

9. Raghu G, Rochwerg B, Zhang Y, et al. An official ATS/ERS/JRS/ALAT clinical practice guideline: treatment of idiopathic pulmonary fibrosis. An update of the 2011 clinical practice guideline. Am J Respir Crit Care Med. 2015;192:e319. https://doi.org/10.1164/rccm.201506-1063ST.

10. King TE, Bradford WZ, Castro-Bernardini S, et al. A phase 3 trial of pirfenidone in patients with idiopathic pulmonary fibrosis. N Engl J Med. 2014;370:2083-92. https://doi.org/10.1056/NEJMoa1402582.
11. Richeldi L, du Bois RM, Raghu G, et al. Efficacy and safety of nintedanib in idiopathic pulmonary fibrosis. N Engl J Med. 2014;370:2071-82. https://doi. org/10.1056/NEJMoa1402584.

12. Bonella F, Wijsenbeek M, Molina-Molina M, et al. European IPF patient charter: unmet needs and a call to action for healthcare policymakers. Eur Respir J. 2016;47:597-606. https://doi.org/10.1183/13993003.01204-2015.

13. Jones RCM, Price D, Ryan D, et al. Opportunities to diagnose chronic obstructive pulmonary disease in routine care in the UK: a retrospective study of a clinical cohort. Lancet Respir Med. 2014;2:267-76. https://doi.org/ 10.1016/S2213-2600(14)70008-6.

14. Raghu G, Collard HR, Egan JJ, et al. An Official ATS / ERS / JRS / ALAT Statement : Idiopathic Pulmonary Fibrosis : Evidence-based Guidelines for Diagnosis and Management. 2011;183:788-824. https://doi.org/10.1164/ rccm.2009-040GL.

15. Jones PW, Quirk FH, Baveystock CM, et al. A self-complete measure of health status for chronic airflow limitation. The St. George's respiratory questionnaire. Am Rev Respir Dis. 1992;145:1321-7. https:/doi.org/10.1164/ajrccm/145.6.1321.

16. Wells AU. Managing diagnostic procedures in idiopathic pulmonary fibrosis. Eur Respir Rev. 2013;22:158-62. https://doi.org/10.1183/09059180.00001213.

17. Collard HR, Tino G, Noble PW, et al. Patient experiences with pulmonary fibrosis. Respir Med. 2007;101:1350-4. https://doi.org/10.1016/j.rmed.2006.10.002.

18. Purokivi M, Hodgson U, Myllärniemi M, et al. Are physicians in primary health care able to recognize pulmonary fibrosis? Eur Clin Respir J. 2017;4: 1290339. https://doi.org/10.1080/20018525.2017.1290339.

19. Cottin V, Bergot E, Bourdin A, et al. Adherence to guidelines in idiopathic pulmonary fibrosis: a follow-up national survey. ERJ open Res. 2015;1:322015. https://doi.org/10.1183/23120541.00032-2015.

20. Schoenheit G, Becattelli I. Cohen a. H. Living with idiopathic pulmonary fibrosis: an in-depth qualitative survey of European patients. Chron Respir Dis. 2011;8:225-31. https://doi.org/10.1177/1479972311416382.

21. Kreuter M, Ehlers-Tenenbaum S, Palmowski K, et al. Impact of comorbidities on mortality in patients with idiopathic pulmonary fibrosis. PLoS One. 2016; 11:e0151425. https://doi.org/10.1371/journal.pone.0151425.

22. Putman RK, Hatabu H, Araki T, et al. Association between interstitial lung abnormalities and all-cause mortality. JAMA. 2016;315:672-81. https://doi. org/10.1001/jama.2016.0518.

23. Hoyer $\mathrm{N}$, Wille $\mathrm{MMW}$, Thomsen $\mathrm{LH}$, et al. Interstitial lung abnormalities are associated with increased mortality in smokers. Respir Med. 2018;136:77-82. https://doi.org/10.1016/J.RMED.2018.02.001.

24. Rosas IO, Ren P. Avila $\mathrm{N}$ a., et al. early interstitial lung disease in familial pulmonary fibrosis. Am J Respir Crit Care Med. 2007;176:698-705. https:// doi.org/10.1164/rccm.200702-254OC.

25. Grufstedt HK, Shaker SB, Konradsen H. Validation of the COPD assessment test (CAT) in patients with idiopathic pulmonary fibrosis. Eur Clin Respir J. 2018;5:1530028. https://doi.org/10.1080/20018525.2018.1530028.

26. Cottin V, Richeldi L. Neglected evidence in idiopathic pulmonary fibrosis and the importance of early diagnosis and treatment. Eur Respir Rev. 2014; 23:106-10. https://doi.org/10.1183/09059180.00008613.

27. Ley B, Collard HR. Epidemiology of idiopathic pulmonary fibrosis. Clin Epidemiol. 2013;5:483-92. https://doi.org/10.2147/CLEP.S54815.

28. Nalysnyk L, Cid-Ruzafa J, Rotella P, et al. Incidence and prevalence of idiopathic pulmonary fibrosis: review of the literature. Eur Respir Rev. 2012; 21:355-61. https://doi.org/10.1183/09059180.00002512.

29. Fernández Pérez ER, Daniels CE, Schroeder DR, et al. Incidence, prevalence, and clinical course of idiopathic pulmonary fibrosis a population-based study. Chest. 2010;137:129-37. https://doi.org/10.1378/chest.09-1002.

Ready to submit your research? Choose BMC and benefit from:

- fast, convenient online submission

- thorough peer review by experienced researchers in your field

- rapid publication on acceptance

- support for research data, including large and complex data types

- gold Open Access which fosters wider collaboration and increased citations

- maximum visibility for your research: over $100 \mathrm{M}$ website views per year

At $\mathrm{BMC}$, research is always in progress.

Learn more biomedcentral.com/submission 